\title{
Wave energy conversion systems: optimal localization procedure
}

\author{
G. Benassai ${ }^{1}$, M. Dattero ${ }^{2}$ \& A. Maffucci ${ }^{1}$ \\ ${ }^{I}$ Department of Applied Sciences, University of Naples Parthenope, Italy \\ ${ }^{2}$ Coastal Risk, Department of Applied Sciences, \\ University of Naples Parthenope, Italy
}

\begin{abstract}
Wave energy is a renewable and pollution-free energy source that has a potential world-wide contribution to the electricity market estimated in the order of 2,000 $\mathrm{TWh} /$ year, which represents about $10 \%$ of the world's electricity consumption with an investment cost of EUR 820 billion. Sea waves have one of the highest energy densities among the Renewable Energy Sources (RES). Today, the largest problem in harvesting wave energy is obtaining reliability of the technology and bringing the cost down.

The main types of wave energy converters are:

- The oscillating water column, which consists of a partially submerged, hollow structure open to the sea below the water line.

- Overtopping devices that collect the water of incident waves in order to drive one or more low head turbines.

- Point absorbers (floating or mounted on the sea bed), which usually provide a heave motion that is converted by mechanical, magnetic and/or hydraulic systems in linear or rotational motion for driving electrical generators.

- Surging devices that exploit the horizontal particle velocity in a wave to drive a deflector or to generate the pumping effect of a flexible bag facing the wave front.

Obviously the amount of available energy depends on the different distribution of the wave energy on the world coastlines. The most energetic sites are situated on the west coasts of the oceans at middle latitudes. European and Australian west coasts reach amounts of $80 \mathrm{~kW} / \mathrm{m}$ of available wave energy; in
\end{abstract}


fact, the first "wave farms" have been installed in Portugal and Scotland where the energy due to the waves reaches these highest values.

The power in a wave is proportional to the square of the amplitude and to the period of the motion. Therefore, long period $(>7-10 \mathrm{~s})$, large amplitude $(>2 \mathrm{~m})$ waves have energy fluxes commonly averaging between 40 and $70 \mathrm{~kW}$ per m width of oncoming wave. Situated at the end of the long, stormy fetch of the Atlantic, the wave climate along the western coast of Europe is characterized by particularly high energy.

In the Mediterranean basin, the annual power level off the coasts of the European countries varies between 4 and $11 \mathrm{~kW} / \mathrm{m}$, the highest values occurring in the area of the south-western Aegean Sea. In the Thyrrenian Sea, this lowest value of $4 \mathrm{~kW} / \mathrm{m}$ is acceptable as a limit for possible location of an offshore wave farm.

In order to identify the best sites and to optimize the location of new wave farms offshore of the coastlines of the Campania region (South of Italy), the significant wave height data set of ISPRA has been used, on which the Italian Wave Atlas is based. The wave buoys data are useful to calibrate the wave prediction model WWIII implemented by the Department of Applied Sciences of the University Parthenope, which simulates the most significant wave storm events of the last ten years. This procedure has been used to produce in the recent past a risk assessment of the Campanian coastlines to the wave impact, so it can also be used to evaluate the potential wave energy to be converted offshore of the Campanian coasts.

Keywords: wave energy, optimal localization, wave farms.

\section{Introduction}

Among the sources of clean renewable and inexhaustible energy, the one that probably has in itself the largest margins of development is certainly the exploitation of wave energy. In fact, water is about 800 times denser than air, so the exploitation of wave power could provide an amount of energy much higher than that of wind energy; both wave and current energy conversion are an enormous potential in almost all coastal zones of the world.

The west coasts of Europe are the places where the energy available per meter of coast is among the largest in the world. Recent studies estimated that about $320 \mathrm{GW}$ power are available from the waves on the North-Eastern coastline of the Atlantic Ocean with values of energy per meter of coast ranging from 25 $\mathrm{kW} / \mathrm{m}$ offshore of the Canary Islands to $70 \mathrm{~kW} / \mathrm{m}$ offshore the coastlines of Scotland.

In the Mediterranean Sea, the power available is estimated to be about 30 $\mathrm{GW}$, with power values ranging from $4 \mathrm{~kW} / \mathrm{m}$ to $13 \mathrm{~kW} / \mathrm{m}$ (southeast Aegean Sea).

The methods being pursued to try to exploit the enormous availability of this kind of energy have been very different; we will make a brief description of the most used systems, classifying them according to the mechanisms of energy conversion. 


\subsection{Oscillating water column}

The OWC device comprises a partly submerged concrete or steel structure, open below the water surface, inside which air is trapped above the water free surface. The oscillating motion of the internal free surface produced by the incident waves makes the air to flow through a turbine that drives an electric generator. The axial-flow Wells turbine, invented in the late 1970's, has the advantage of not requiring rectifying valves. It has been used in almost all prototypes.

Several OWC prototypes have been built in on the shoreline in Norway, China, UK (LIMPET), Portugal (Pico Island); incorporated in a breakwater (in the harbour of Sakata, NW Japan) or placed outside it (Trivandrum, India).

\subsection{Overtopping devices}

This typology includes the Wave Dragon, one of the systems that achieved in recent years very interesting results. The Wave Dragon is composed of two long arms of $130 \mathrm{mt}$. each, which are responsible for the waves to reflect and convey to the central unit that is placed at an elevated level from the sea surface, where a series of vertical Kaplan turbines are located.

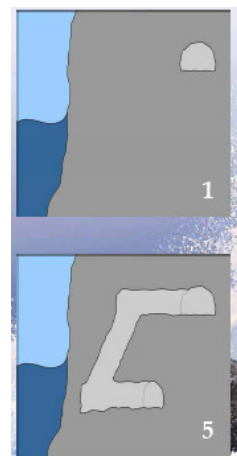

Figure 1: Scheme of an oscillating water column.
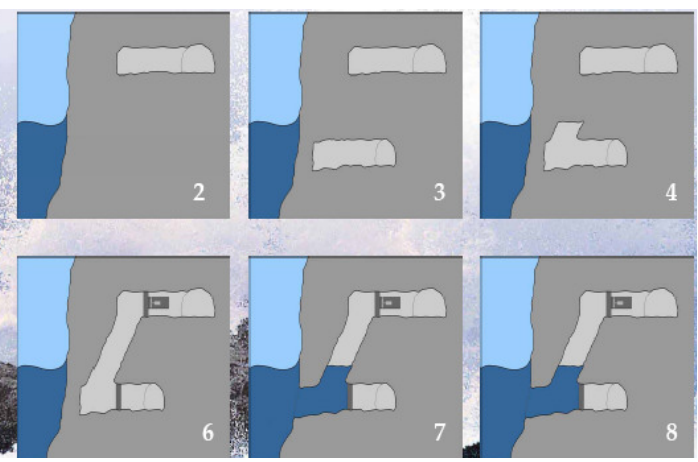

8

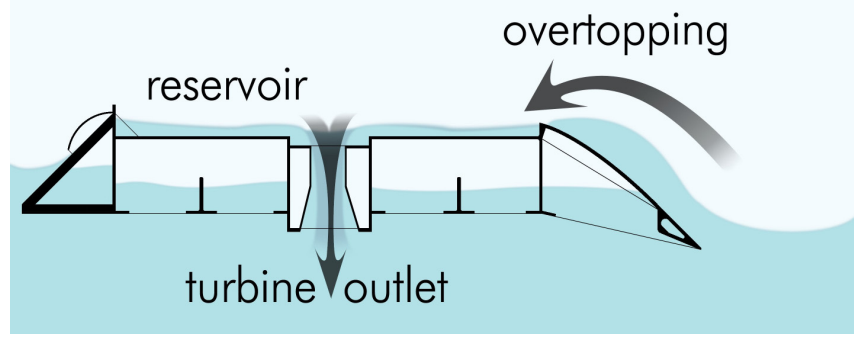

Figure 2: Scheme of the Wave Dragon. 
The water that overflows in the basin, driven only by the force of gravity, passes through the Kaplan low head turbines. Today, the maximum power obtainable from any Wave Dragon is of $4 \mathrm{MW}$, but in future years units of 7 MW will be implemented.

\subsection{Archimedes Wave Swing}

The AWS consists of an upper part (the floater) of the underwater buoy that moves up and down in the wave while the lower part (the basement or pontoon) stays in position. The periodic changing of pressure in a wave initiates the movement of the upper part. The floater is pushed down under a wave top and moves up under a wave trough. To be able to do this, the interior of the system is pressurised with air and serves as an air spring. The air spring, together with the mass of the moving part, is resonant with the frequency of the wave. The mechanical power required to damp the free oscillation is converted to electrical power by means of a Power Take Off system (PTO). The PTO consists of a linear electrical generator and a gas- (nitrogen-) filled damping cylinder.

\section{Suitable devices and locations for installing wave farms in Italy}

A preliminary assessment of the most suitable device as a wave energy conversion system passes through its survivability. In fact, wave energy devices are placed in regions of high incident wave power, which is normally related to very rough sea states that have to be considered for the design. The absence of clear and reliable design procedures accounting for loads arising in such an environment makes it difficult to conduct wave energy projects with sufficient planning safety. This implies that, to a greater extent than for other renewable energy technologies, the survivability plays a decisive role for the success of ocean wave energy projects. In this context the AWS has the advantage to be a completely submerged device, which brings along considerable plus for the design stability.

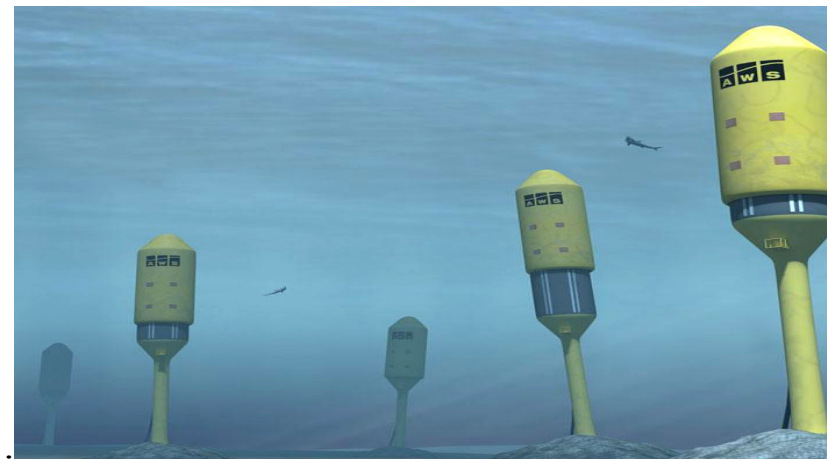

Figure 3: $\quad$ Scheme of a series of AWSs. 
A preliminary assessment of the most suitable locations for wave farm installation starts with the spatial analysis of the sea state characteristics in order to establish the potential available energy per meter of coastline. The potential amount of wave power available on the Italian coasts has been established by wave data analysis derived from measurements taken from buoys located along the Italian coastlines belonging to the National Wave Network (RON) which is run by ISPRA.

According to these good quality data, the best energetic coastal sites are found on the Sardinian and Sicilian coasts.

The amount of incident wave power is given by the following equation:

$$
\mathrm{J}=0.42 \times \mathrm{Hs}^{2} \times \mathrm{T}_{\mathrm{P}}
$$

The 0.42 multiplier in the above equation is exact for any sea state that is well represented by a two-parameter Bretschneider Spectrum, but it could range from 0.3 to 0.5 , depending on the shape of the wave spectrum and on the relative amounts of energy in sea and swell components. Tab. 1 shows the energy amount available from waves of given height and period.

Using the data collected in the Italian wave Atlas by ISPRA, we are able to obtain a fairly satisfactory estimate of the available energy in coastal sites where a RON buoy is located. It is well-known that the western coast of Sardinia is the worst location for wave storms, so the best Italian location for exploitation of wave energy. The wave energy calculation implemented for the buoy of Alghero gives an average energy of about $11 \mathrm{~kW} / \mathrm{m}$, according to the values expected for the most energetic sites of the Mediterranean.

\section{Suitable locations for installing wave farms in Campanian coasts}

The buoy of Ponza, located offshore of the coastlines of Lazio, is the closest to the coastlines of Campania region and so its data have been used to analyse the wave energy potential in Campanian coasts.

The value of wave energy calculated for the buoy of Ponza is significantly lower than Alghero, giving an average value of about $4 \mathrm{~kW} / \mathrm{m}$. These calculations are valid for the most energetic directions, that is between $225^{\circ} \mathrm{N}$ and $285^{\circ} \mathrm{N}$.

Table 1: $\quad$ Power generation (KW) per classes of wave height and period.

\begin{tabular}{|c|c|c|c|c|c|c|}
\hline \multicolumn{7}{|c|}{ Power Generation (kW) per wave height and period for each unit } \\
\hline & \multicolumn{7}{|c|}{ Wave Period (sec) } \\
\hline Wave Height & 5 & 6 & 7 & 8 & 9 & 10 \\
\hline 1 & 23.6 & 19.7 & $\mathbf{1 6 . 9}$ & 14.8 & 13.1 & 11.8 \\
\hline 2 & 94.6 & 78.8 & 67.5 & 59.1 & 52.5 & 47.3 \\
\hline 3 & 153.9 & 128.3 & 109.9 & 96.2 & 85.5 & 77.0 \\
\hline 4 & 189.1 & 157.6 & 135.1 & 118.2 & 105.1 & 94.6 \\
\hline 5 & 189.1 & 157.6 & 135.1 & 118.2 & 105.1 & 94.6 \\
\hline
\end{tabular}


In order to obtain comparative results of the obtainable wave power for the Campanian coastlines with a sufficient spatial density, the $3^{\text {rd }}$ generation wave model Wave Watch III was run with the simulations of the storms of the last 10 years. It was demonstrated that the data collected by the buoy of Ponza are in good agreement with the simulations derived through the implementation of Wave Watch III model for the most exposed coastal sites of the Campanian coasts. The model was applied to the Gulf of Naples referenced to two classes of wave storms: the first class of sea storms, which is showed more frequently, is exemplified by the storm of December 1999, with waves coming from SouthWest and West. The second class of storms is exemplified by the storm of December 2004, with waves coming from South.

\section{Archimedes Wave Swing possible installations on the Campanian coasts}

Either in the most frequent case of waves coming from west - south west, like the sea storm of 1999, or in the less frequent case of waves coming from the south, like the sea storm of 2004, the most suitable sites for the installation of wave farms were found to be the most exposed coastlines, that is the coastlines not sheltered from the Isles of Capri and Ischia. This leads to the offshore coastlines of Ischia and Capri and the offshore coastlines of Sorrento peninsula For example, the sites offshore the Isle of Ischia, illustrated in fig. 5 or the site offshore the Sorrento peninsula, on the Amalfi coast, illustrated in fig. 6, are all suitable because they gain interesting energy values in both types of sea storms.

A comparison between the energy values of Ponza and these coastal sites have shown that, at a first stage of analysis, there are minor differences. So, in absence of available field data on the Campanian coastal sites, it can be assumed that the available data of the buoy of Ponza can be used for the sites offshore the coastal sites of Ischia and Sorrento.
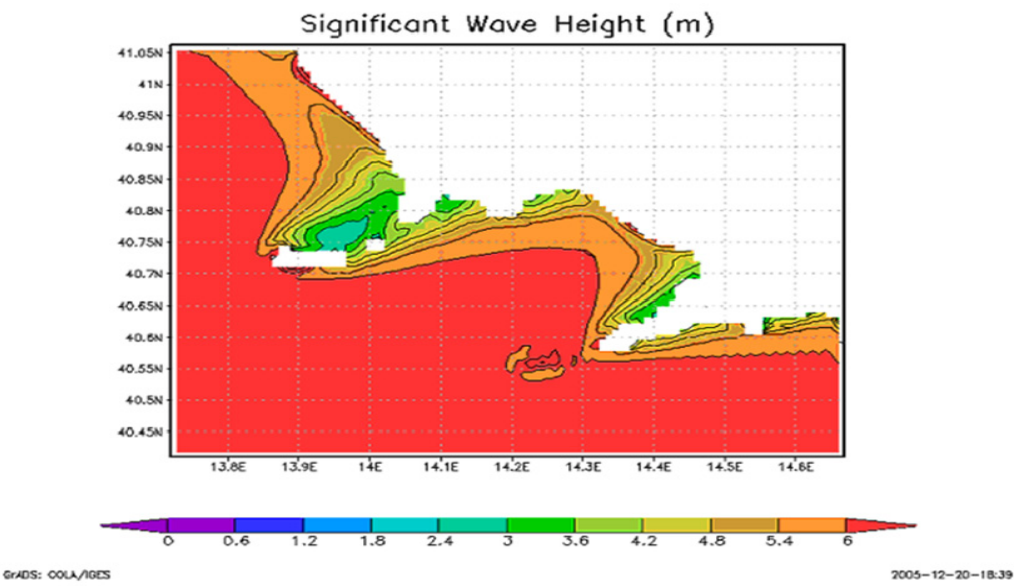

Figure 4: $\quad$ WWIII simulation of December 2004 storm in the Gulf of Naples. 


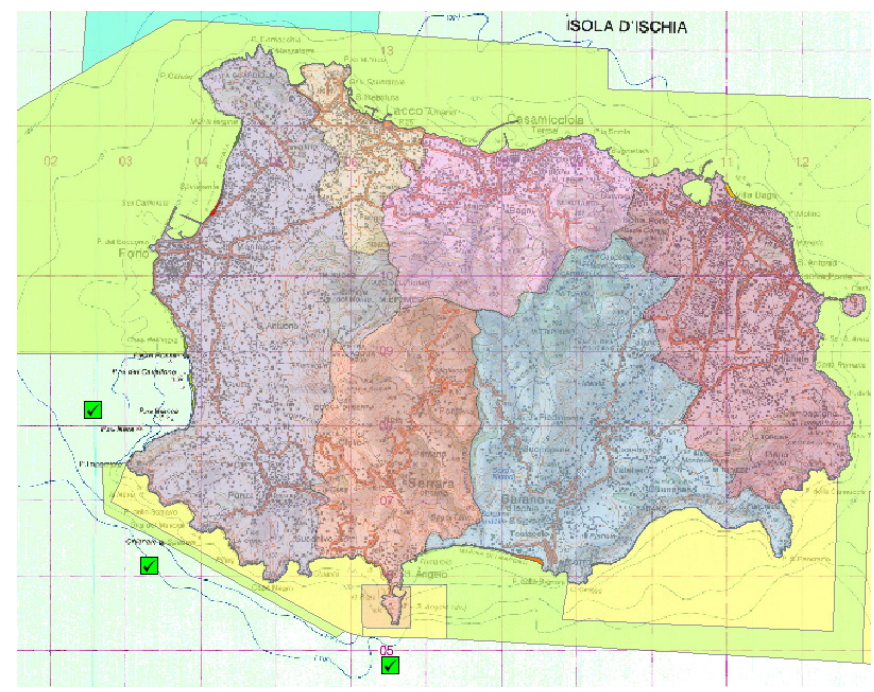

Figure 5: Optimal AWS localization in Campania (offshore of Ischia).

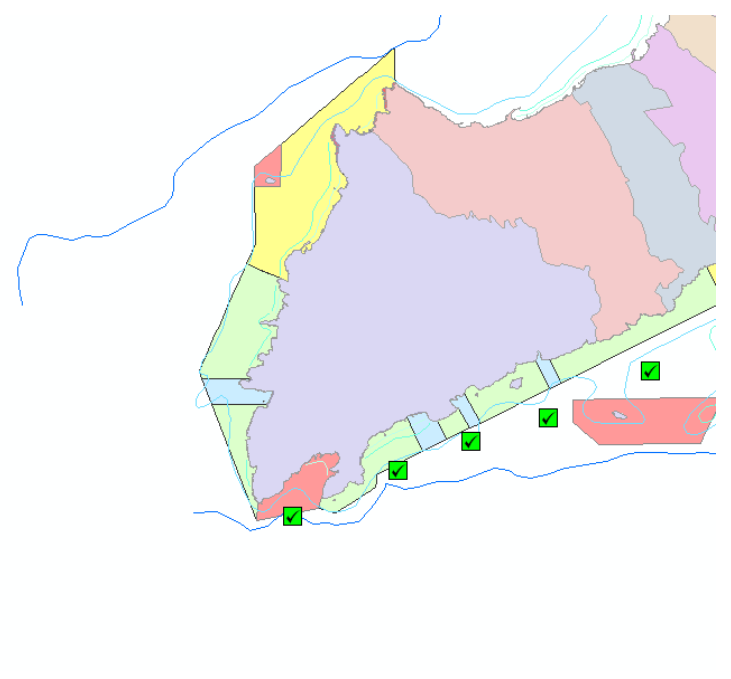

Figure 6: Optimal AWS localization in Campania (offshore of Sorrento).

\subsection{AWS economic analysis}

As already stated, the use of the AWS on Campanian coasts is particularly suitable for the absence of impact on the landscape because of its location a few meters below the surface; this permits the passage of small and medium vessels above the wave farm. 
Table 2: $\quad$ Annual profit for wave energy selling.

\begin{tabular}{|l|l|}
\hline \multicolumn{2}{|c|}{ ANNUAL PROFIT (€) FOR AWS (200 MWlyear) } \\
\hline 1.500 .000 & AWS investment + installation price \\
\hline 200.000 & Kw for each year \\
\hline 0.098 & Energy sell price for kw \\
\hline 19.600 & Total profit for energy sale \\
\hline 20.000 & Profit for the Green Certificates sale \\
\hline 0.34 & GSE bonus for kw \\
\hline 68.000 & Total profit for the GSE bonus \\
\hline 107.600 & Total profit for each year \\
\hline
\end{tabular}

Table 3: $\quad$ Cash flow for AWS.

\begin{tabular}{|c|c|c|}
\hline \multicolumn{3}{|c|}{ CASH FLOW FOR AWS(200 MWlyear) } \\
\hline year & Profit for year $(€)$ & Investment recovered $(€)$ \\
\hline 1 & 107.600 & -1.392 .400 \\
\hline 2 & 107.600 & -1.284 .800 \\
\hline 3 & 107.600 & -1.177 .200 \\
\hline 4 & 107.600 & -1.069 .600 \\
\hline 5 & 107.600 & -962.000 \\
\hline 6 & 107.600 & -854.400 \\
\hline 7 & 107.600 & -746.800 \\
\hline 8 & 107.600 & -639.200 \\
\hline 9 & 107.600 & -531.600 \\
\hline 10 & 107.600 & -424.000 \\
\hline 11 & 107.600 & -316.400 \\
\hline 12 & 107.600 & -208.800 \\
\hline 13 & 107.600 & -101.200 \\
\hline 14 & 107.600 & +6.400 \\
\hline 15 & 107.600 & +114.000 \\
\hline 16 & 107.600 & +221.600 \\
\hline 17 & 107.600 & +329.200 \\
\hline 18 & 107.600 & +436.800 \\
\hline 19 & 107.600 & +544.400 \\
\hline 20 & 107.600 & +652.200 \\
\hline
\end{tabular}

The average value of available energy of about $4 \mathrm{~kW} / \mathrm{m}$ was assumed for the following economic calculations. Using the available data for the buoy of Ponza a production of energy of about $160 \mathrm{~kW}$ for each AWS can be estimated. The annual energy production can thus be estimated at about $200 \mathrm{MW}$ per year for each device. These results have been used for subsequent calculation. 


\subsection{AWS cash flow and total profits}

The Italian Energetic Agency rates for the energy payment have been considered, on the basis of an annual energy production of 200 MW. Each AWS costs approximately $1.500 .000 €$ including the installation cost. In the next table the rates payout for a device with a production of $200 \mathrm{MW}$ for year have been given.

In table 3 there is the cash flow of the AWS, the investment will be recovered in 14 years and after 20 years (that is the duration of the contract with the energy distributor) the investor will gain a profit of $650.000 €$.

\section{Conclusions}

The conversion of wave energy is now an important resource particularly for the most exposed coastal areas. This is the reason why that the major projects for installation of wave energy farms have been made in Great Britain, Denmark and Portugal which have the most interesting wave energy resources on their coasts. The Archimedes Wave Swing and other devices, such as the Wave Dragon, are already in a competitive position to balance and in some cases overcome in terms of performance and cost the results obtained in recent years by wind power.

Of course even for the most energetic coastal sites, a careful analysis of the costs and the benefits of the investment must be implemented. In this paper we have considered the installation of small wave farms offshore the most exposed coasts of Campania region in order to calculate the pay-back time of the investment.

At present the most suitable device is certainly the Archimedes Wave Swing both for the amount of obtainable energy and for its characteristics of being submerged at a depth higher than 6 meters from the surface, thus limiting the environmental impact. For this device the calculations of pay-back time demonstrated that a period of 14 years is sufficient for cost recovering, and at the end of the period of the contract with the Italian State Energy Agency there is a net gain of 650.000 Euros. These already promising results may improve substantially with a careful cost optimization, which can be achieved with higher efficiency of energy converters and lower cost of energy plant installation.

The present analysis, although not exhaustive, has demonstrated the real potential of wave energy conversion for the considered locations. The proposed solution minimizes the possible interactions between the energy devices and the tourist or trade ship routes, as well as any other constraint regarding marine protected areas, archaeological sites, etc.

\section{References}

[1] EPRI - Guidelines for Preliminary Estimation of power production by offshore wave energy conversion devices

[2] L.A. St. Germain, A Case Study of Wave Power Integration into the Ucluelet Area Electrical Grid, Carleton University, 2003 
[3] Alain Clément, Pat McCullen, Antònio Falcao, Antonio Fiorentino, Fred Gardner, Karin Hammarlund, George Lemonis, Tony Lewis, Kim Nielsen, Simona Petroncini, M.-Teresa Pontes, Phillippe Schild, Bengt-Olov Sjostrom, Hans Christian Sørensen, Tom Thorpe, Wave energy in Europe: current status and Perspectives, Renewable and Sustainable Energy Reviews 6 (2002), 405-431

[4] Atlante delle onde e dei mari italiani - APAT, Università degli Studi di Roma Tre

[5] Thorpe, An Overview of wave energy technologies: Status, Performance and Costs, Wave power: moving towards commercial Viability, 30 November 1999

[6] T. Thorpe, "Ocean Wave Energy: Energetech" presented at 5th BASE International Investment Forum, Bonn, Germany, June 2004.

[7] S. H. Salter, "Wave Power" Nature, vol. 249, pp. 720-724, 1974.

[8] J. P. Kofoed, P. Frigaard, E. Friis-Madsen, and H. C. Sorensen, "Prototype Testing of the Wave Energy Converter Wave Dragon" presented at World Renewable Energy Congress VIII (WREC 2004), 2004.

[9] Y. Washio, H. Osawa, and T. Ogata, "The open sea tests of the offshore floating type wave power device "Mighty Whale" -characteristics of wave energy absorption and power generation," 2001.

[10] A. F. d. O. Falcao, "Control of an Oscillating-Water-Column Wave Power Plant for Maximum Energy Production" Applied Ocean Research, vol. 24, pp. 73-82, 2002. 107

[11] I. Glendenning, "Wave Power - A Real Alternative?" Ocean Management, vol. 4, pp. 207-240, 1978.

[12] S. Raghunathan, "The Wells Air Turbine for Wave Energy Conversion" Progress in Aerospace Sciences, vol. 31, pp. 335-386, 1995.

[13] T. J. T. Whittaker, "Learning from the Islay Wave Power Plant" presented at IEE Colloquium on Wave Power; An Engineering and Commercial Perspective, 13 March 1997.

[14] Wavegen, "Islay Limpet Project Monitoring Final Report" ETSU V/06/00180/00/Rep, 2002.

[15] T. Setoguchi, S. Santhakumar, M. Takao, T. H. Kim, and K. Kaneko, " $A$ Modified Wells Turbine for Wave Energy Conversion" Renewable Energy, vol. 28, pp. 79-91, 2003.

[16] V. S. Raju, M. Ravindran, and U. A. Korde, "Experiments on the Oscillating Water Column Wave Energy System" OCEANS, vol. 16, pp. 938-943, 1984. 112 